\title{
O branqueamento de capitais, a prova indiciária e os princípios da legalidade e ampla defesa
}

\author{
Money laudering, the circumstancial evidence and \\ the principles of legality and legal defense
}

\section{Sólon Cícero Linhares}

Mestre pela Universidade Federal do Paraná, (UFPR), professor de Direito Penal da Pontifícia Universidade Católica do Paraná (PUCPR), Curitiba, PR - Brasil, e-mail: solonlinhares@hotmail.com

\section{Resumo}

Por ser um crime recente, inicialmente serão feitas considerações sobre os conceitos e o iter do delito de lavagem de dinheiro, bem como as espécies de provas, mormente a prova indiciária. Em seguida, a discussão se pauta na utilização da prova por indícios do delito antecedente como prova substancial a subsidiar condenação criminal por crime da Lei 9.613/1990. Analisando-se decisões jurisprudenciais, demonstra-se a evolução do pensamento jurídico e jurisprudencial que este instituto traz. Trabalham-se comentários sobre argumentações defensivas em sede acadêmica, especificamente no que se refere aos princípios da ampla defesa e legalidade. Por fim, conclui-se não restar dúvidas de que é perfeitamente legal a utilização das provas indiciárias do crime antecedente para subsidiar condenação criminal por delitos de lavagem de dinheiro, uma vez que se tratam 
de delitos autônomos (antecedente e lavagem), com previsão legal específica, e ainda porque em perfeita sintonia com o sistema Processual Penal Brasileiro.

Palavras-chave: Lavagem de Dinheiro. Delito Antecedente. Provas Indiciárias. Presunções. Princípio da Ampla Defesa.

\section{Abstract}

Being a recent phenomenon, we discuss the concepts and the iter of money laundering crime as well as the kinds of evidence, especially the circumstantial one. Then behind the discussion on the use of proof by evidence of prior offenses as substantive evidence to support conviction for the crime of Law 9.613/1990. Analyzing the court decisions, it demonstrates the evolution of legal thought and jurisprudence that this institute behind. Works to comment on arguments defensive academic home, specifically with regard to the principles of legality and legal defense. Finally, there is no doubt that the use of circumstantial evidence of the predicate offense to support a criminal conviction for crimes of money laundering is perfectly legal, since it is autonomous crimes (preceding and washing), expected legal specific and because in perfect harmony with the Brazilian criminal procedure.

Keywords: Money Laudering. Precedent Crime. Circumstancial evidences. Presumptions. Principle of Legal Defense. Principle of legality.

Sem dúvidas, a lavagem de capitais e a utilização da prova indiciária do delito antecedente como fundamento para condenação são um tema polêmico em sede acadêmica, mormente no que se refere ao viés probatório e aos princípios constitucionais da legalidade e ampla defesa.

A Lei 9.613, de 3 de março de 1998, que trata dos crimes de lavagem ou ocultação de bens, direitos ou valores no Brasil, no seu preceito secundário, estipula a pena de reclusão de três a dez anos para quem ocultar ou dissimular a natureza, origem, localização, disposição, movimentação ou propriedade de bens, direitos ou valores provenientes, direta ou indiretamente, de crime de tráfico ilícito de substâncias entorpecentes ou 
drogas afins, terrorismo e seu financiamento, contrabando ou tráfico de armas, munições ou material destinado à sua produção, extorsão mediante sequestro, contra a administração pública, inclusive a exigência, para si ou para outrem, direta ou indiretamente, de qualquer vantagem, como condição ou preço para a prática ou omissão de atos administrativos, contra o sistema financeiro nacional, praticado por organização criminosa ou praticado por particular contra a administração pública estrangeira.

Em brilhante trabalho acadêmico sobre ações internacionais de combate à lavagem de dinheiro em instituições financeiras, a autora Clarisse de Almeida e Alvarenga (2003) discorre sobre os vários conceitos sobre o crime de lavagem de dinheiro, dentre eles o de Peter Lilley (2001, p. 18), o qual entende por lavagem de dinheiro "o método por meio do qual os recursos provenientes do crime são integrados aos sistemas bancários e ao ambiente de negócios do mundo todo".

O Grupo de Ação Financeira Internacional (GAFI) desde 1988 vem trabalhando sobre o tema e define a lavagem de dinheiro como o processo ou o processamento de atividades delitivas destinado a ocultar sua origem ilegal.

Ou seja, trata-se da ocultação ou o disfarce dos capitais oriundos de atividades ilegais (tráfico de drogas, tráfico de armas, ações de pedófilos, entre outras) visando a sua reinserção ao mercado legal, não rara vezes realizadas por meio de atividades bancárias ou qualquer outra espécie de negócio formal.

Muito se escreve sobre as fases ou o iter do delito de branqueamento de capitais; para tanto, preferimos o método utilizado pelo autor Luciano Baldi (2009, p. 8), no trabalho que teve por orientação este subscritor:

o Conselho de Controle de Atividades Financeiras (COAF) adota como modelo explicativo do processo de lavagem de dinheiro aquele elaborado pelo GAFI ${ }^{1}$ e que divide o processo em três fases: colocação (placement),

\footnotetext{
1 Financial Action Task Force/Grupe d'action Finaciére, citado neste trabalho apenas como GAFI.
} 
estratificação (layering) e integração (integration). Cabe ressaltar apenas uma pequena diferença, a unidade de inteligência financeira do Brasil usa em lugar do termo estratificação a palavra ocultação.

Outro ponto importante a ressaltar é que a esquematização do processo feita pelo COAF/GAFI tem valor apenas didático, porque as suas fases podem ocorrer de forma simultânea, ou seja, aparecerem superpostas conforme o instrumento ou método empregado pelo "lavador". Conforme o COAF as fases do processo de lavagem ${ }^{2}$ podem ser detalhadas da seguinte forma:

1. DA COLOCAÇÃO

A primeira etapa do processo é a colocação do dinheiro no sistema econômico. Objetivando ocultar sua origem, o criminoso procura movimentar o dinheiro em países com regras mais permissivas e naqueles que possuem um sistema financeiro liberal. A colocação se efetua por meio de depósitos, compra de instrumentos negociáveis ou compra de bens. Para dificultar a identificação da procedência do dinheiro, os criminosos aplicam técnicas sofisticadas e cada vez mais dinâmicas, tais como o fracionamento dos valores que transitam pelo sistema financeiro e a utilização de estabelecimentos comerciais que usualmente trabalham com dinheiro em espécie.

2. DA OCULTAÇÃO

A segunda etapa do processo consiste em dificultar o rastreamento contábil dos recursos ilícitos. O objetivo é quebrar a cadeia de evidências ante a possibilidade da realização de investigações sobre a origem do dinheiro. Os criminosos buscam movimentá-lo de forma eletrônica, transferindo os ativos para contas anônimas - preferencialmente, em países amparados por lei de sigilo bancário - ou realizando depósitos em contas "fantasmas".

3. DA INTEGRAÇÃO

Nesta última etapa, os ativos são incorporados formalmente ao sistema econômico. As organizações criminosas buscam investir em empreendimentos que facilitem suas atividades - podendo tais sociedades prestarem serviços entre si. Uma vez formada a cadeia, torna-se cada vez mais fácil legitimar o dinheiro ilegal.

2 CONSELHO DE CONTROLE DE ATIVIDADES FINANCEIRAS (COAF). Disponível em <https://www. coaf. fazenda.gov.br/conteudo/sobre-lavagem-de-dinheiro-1/fases.> Acesso em: 25 fev. 2009. 
A definição da segunda fase do processo de lavagem merece especial destaque, o delito em discussão tem como parte essencial de seu "modus operandi" a rotina de eliminação de evidências, portanto, quando praticado por profissionais competentes, plausivelmente, pode não deixar nenhuma prova direta, cabal de sua existência restando apenas elementos de prova indireta.

Ultrapassada esta análise inicial sobre a estrutura conceitual do delito, necessário se faz enfrentar o sistema probatório do Direito Processual Penal Brasileiro, especificamente no que diz respeito às espécie de provas - direta e indireta.

Fernando Capez (2005, p. 260) define prova como "qualquer meio de percepção empregado pelo homem para verificar a validade e a veracidade de uma alegação". A prova pode ser estudada a partir de suas espécies direta ou imediata e indireta ou mediata (ou ainda, como preferem alguns catedráticos no tema, provas indiciárias).

As primeiras são aquelas que não necessitam de um processo ou método indutivo ou lógico para a constatação do fato a ser provado, como, por exemplo, a confissão, o laudo que atesta a falsificação grosseira do cheque, ou seja, são provas que não exigem raciocínio lógico ou juízo de valor apurado para se compreender o resultado do fato típico.

Por sua vez a prova indireta, mediata ou indiciária, são aquelas que exigem do seu intérprete uma cadeia de ideias lógicas, utilizando-se de métodos indutivos para se chegar a um resultado prático que permite provar a existência do fato típico.

Sobre o conceito de indício, o Código de Processo Penal, artigo 239, assim dispõe: "Art. 239. Considera-se indício a circunstância conhecida e provada, que, tendo relação com o fato, autorize, por indução, concluir-se a existência de outra ou outras circunstâncias".

Ainda sobre o aspecto conceitual, a notável professora Maria Thereza Rocha de Assis Moura conceitua indícios como "todo rastro, vestígio, sinal e, em geral, todo fato conhecido devidamente provado, suscetível de conduzir ao conhecimento de um fato desconhecido, a ele 
relacionado, por meio de um raciocínio indutivo-dedutivo" (MOURA, 2009, p. 41).

Neste sentido, o professor Fernando Capez (2005, p. 334) se manifesta: "indício é toda a circunstância conhecida e provada, a partir da qual, mediante raciocínio lógico, pelo método indutivo, obtém-se a conclusão sobre um fato".

A orientação jurisprudencial sobre o tema, não diverge do que foi referido, senão vejamos:

[...] indício, como prelecionam alguns catedráticos, advém da palavra latina indiciare (= indicar, descobrir, revelar, dar a entender). Outros ligam o termo à palavra index que expressava o dedo indicador, o objeto ou um fato indicado. Para o magistral Mittermayer, indício "é um fato em relação tão precisa com outro fato, que, de um, o juiz chega ao outro por uma conclusão natural" (Tratado da prova em matéria criminal, 1871, p. 497) (Tacrim/SP, Rel. Silva Pinto, ACR, RJD 6/137).

Neste diapasão, para uma perfeita compreensão do tema, é imprescindível deixar consignado que indícios não se confundem com presunções, primeiro porque indícios, como visto, têm natureza própria, elementos específicos (fatos e circunstancias) que o tornam instituto perfeito, individualizável e acabado.

Presunção, por sua vez, conforme bem definiu o professor Sebastião Sérgio da Silveira, ${ }^{3}$

ao contrário de indício [...] significa um pré-julgamento, com a consideração prévia de que algo é verdadeiro ou falso, mesmo antes de sua demonstração. Como regra, as presunções determinam a aceitação da veracidade ou falsidade de um fato (presunção absoluta), ou determinam a inversão do ônus da prova (presunção relativa), àquele que pretende demonstrar o contrário.

3 Disponível em: <http://www.buscalegis.ufsc.br/revistas/index.php/buscalegis/article/viewFile/17080/ 16644>. Acesso em: 4 maio 2010. 
No indício não há o pré-julgamento, reconhecendo que o raciocínio indutivo ou dedutivo (mais apropriado), sempre tem como ponto de partida o fato conhecido, utilizado como meio, para se chegar ao desconhecido. A indução (ou a dedução) utilizada na interpretação dos indícios não pode ser confundida jamais com o juízo preconcebido existente nas presunções. Aliás, Vicente de Azevedo, ${ }^{4}$ de forma magistral estabeleceu tal diferença, ao afirmar: "Por outras palavras, eis a diferença entre indício e presunção: indício é uma circunstância ou fato conhecido que serve de guia para descobrir o outro. De um fato conhecido, se deduz outro. O conhecido indica o outro. Presunção é operação mental, a interferência que por via do raciocínio, ou de experiência deduzimos do indício conhecido" (grifos nossos).

Ora, resta evidente que indícios e presunções não se confundem, ainda que alguns insistam neste sentido, uma vez que ambos os institutos têm natureza jurídica distinta, isto é, um trabalha com fatos materiais e conhecidos (indícios), o outro labora com deduções baseadas em experiências preconcebidas (presunções).

O que se propõe, com a compreensão dos elementos que integram o conceito de indício, é reforçar a ideia que a prova decorrente de indícios não é uma prova ilegítima ou "bastarda"; pelo contrário, trata-se de instrumento com a mesma força probante de sua irmã, a prova direta, porque prevista a partir de processo legislativo, produzida no interior de um processo contraditório e ainda estabelecida com parâmetros objetivos e lógicos.

Especificamente sobre o início da ação no delito de lavagem de capitais, a lei no artigo $2^{\circ}, \S 1^{\circ}$, dispõe que a denúncia será instruída com indícios suficientes para a existência do crime antecedente, ou seja, para a propositura da ação penal pelo membro do Ministério Público basta que haja indícios suficientes de provas do crime antecedente.

Assim, diante desta superficial análise sobre as características do delito de lavagem de dinheiro e dos instrumentos probatórios, especificamente no que se refere à prova por indícios, uma questão não pode deixar de ser levantada: a possibilidade da utilização de provas indiciárias

${ }^{4}$ AZEVEDO, 1958, p. 12. 
do crime antecedente para a efetiva condenação por delitos previstos na Lei n. 9.613, de 3 de março de 1998, que trata dos crimes de lavagem ou ocultação de bens, direitos ou valores no Brasil.

Palmilhando neste pensar, é crucial a análise sobre a valoração da prova indiciária, tema este que já vem sendo enfrentado na doutrina e jurisprudência alienígena, mormente a espanhola, americana e argentina. Neste sentido, professor Antonio Dellepiane (2004, p. 103-106) afirma que:

a) os indícios devem achar-se desde logo comprovados e esta comprovação deve ser feita por meio de provas diretas, o que não obsta que essa prova possa ser composta, utilizando-se, para isso, provas diretas imperfeitas, isto é, insuficientes para produzir cada uma isoladamente prova plena;

b) os indícios devem ser submetidos a uma análise crítica, destinada a verificá-los, precisá-los e avaliá-los e da qual terão saído, se não com um valor numérico, pelo menos providos com a etiqueta de graves, medianos ou leves;

c) devem, também, os indícios ser independentes, em vários sentidos;

d) sejam vários, quando não possam dar lugar a deduções concludentes, como as fundadas em leis naturais que não admitem exceção;

e) sejam concordantes, isto é, que se ajustem entre si, de modo a produzirem um todo coerente e natural;

f) as inferências indiciárias sejam convergentes, vale dizer, que todas reunidas não possam levar a conclusões diversas;

g) as conclusões sejam imediatas, o que se deve entender no sentido, de que não se torne, necessário chegar a elas através de uma cadeia de silogismos;

h) as conclusões excluam as hipóteses da ação provável do azar ou da falsificação de prova.

Disto, conclui-se que para se trabalhar com a prova indiciária é necessário seguir critérios objetivos, sem os quais se poderá comprometer todo o conjunto probatório. 
Neste sentido, Luciano Baldi (2009, p. 40), de forma brilhante, traçou o estudo da valoração da prova indiciária e seus critérios, utilizandose dos planos de existência, validade e eficácia, partindo do pressuposto de que a prova nada mais é que um fato processual e, neste sentido, no plano de existência, a prova de natureza indiciária é aquela que decorre de fato ou circunstância que têm vinculação com o fato que se pretende provar. Por sua vez, são fatos e circunstâncias que fazem brotar o indício: o conteúdo de depoimentos ou interrogatórios, vestígios materiais colhidos no exame do corpo de delito, a existência de determinados objeto de posse do possível infrator ou em local a ele relacionado, ou, ainda, onde foi cometida a infração. Já no que se refere ao plano de validade, a prova deve estar desprovida de nulidade jurídica, ou seja, conforme esclareceu o professor Nucci: são válidas e podem ser produzidas no processo penal todas as provas que não contrariem o ordenamento jurídico (NUCCI, 2008, p. 342). Por fim, no que se refere ao plano de eficácia, o citado autor esclarece que

os fatos indiciários devem formar um conjunto que possua harmonia interna com o fato principal que deve ser provado, portanto, a medida da eficácia probatória de um conjunto de indícios contingentes depende, em essência, da concordância dos componentes de tal conjunto e a convergência das inferências que deles resultam (MOURA, 2009, p. 100).

Recentemente o juiz federal Sérgio Fernando Moro, em artigo publicado na Revista do Centro de Estudos Judiciários (2010), demonstrou claramente a complexidade que envolve o estudo do delito de lavagem de dinheiro, especialmente no que se refere à percepção e à constatação da prova do crime, tornando, invariavelmente, muito difícil a demonstração do fato típico, por meio de provas diretas, mormente pelos motivos que envolvem o delito em estudo.

Sendo assim, restaria, conforme bem demonstrado pelo notável magistrado, como meio ou instrumento eficaz para aplicação da lei penal, a prova indiciária. 
Como fundamento, Moro (2010) busca conceitos do direito alienígena, os quais pela importância do tema, merecem serem consignados:

[...]

Em United States v. Golb, 69 F3d 1417 (9th Cr. 1995), entendeu-se que, quando o acusado por crime de lavagem faz declarações de que o adquirente de um avião é um traficante, e quando o avião é modificado para acomodar entorpecentes, pode ser concluído que o dinheiro utilizado na aquisição era dinheiro proveniente de tráfico de entorpecentes; [...]

Em United States v. Reiss, 186 f. 3d 149 (2nd Cir. 1999), a utilização de subterfúgios para o pagamento de um avião envolvendo conhecido traficante foi considerada suficiente para estabelecer a procedência ilícita dos recursos empregados na compra;

[...]

$\mathrm{Na}$ STS 392/2006 entendeu-se que a prova de que o acusado figurava como proprietário de embarcação de alta velocidade em Ceuta (do tipo comumente utilizado para transporte de droga na região do Estreito de Gibraltar), sem ter renda lícita que pudesse justificar tal propriedade, aliada à prova de que a embarcação, na única vez em que utilizada, teria sido conduzida por pessoa com antecedente de crime de tráfico de drogas, era suficiente para caracterizar o crime de lavagem de dinheiro;

Fica evidente a dificuldade que acomete o Estado-Juiz em tornar efetiva a aplicação da lei penal nos crimes de lavagem de capitais, uma vez que as provas materiais do delito não estão dispostas de forma evidente ou muitas vezes sequer existem, porque dissimuladas ou ocultadas pelos sujeitos ativos por meio dos vários processos de "branqueamento".

Resta ao magistrado apenas indícios do cometimento do fato típico, motivo pelo qual a prova indiciária se torna, cada vez mais, para esta espécie de crime, o único instrumento capaz de dar sustentação a uma eventual condenação.

É sabido que vigora no Direito Processual Penal Brasileiro o sistema do livre convencimento motivado do juiz, motivo pelo qual não é dado tratar provas, sejam diretas ou indiretas, com maior ou menor grau de teor probatório, uma vez que tudo vai depender do caso concreto, das 
circunstâncias factuais, as quais formaram um conjunto de provas que darão sustentação à decisão do Estado-Juiz.

Entretanto, não basta apenas a prova indiciária, por si só, isolada, é necessário mais: como visto, é imprescindível que o magistrado exerça o encadeamento lógico do fato ou da circunstancia indiciária ao fato que se pretende provar, utilizando-se de critérios objetivos, do plano de existência, validade e eficácia da prova.

Após toda esta análise, se convencido de que os indícios levam à prova do fato final, ou ainda, de que o conjunto indiciário é robusto de tal forma, que indica o cometimento do ilícito, não há dúvida de que resta devidamente comprovada a prática do crime de lavagem de capitais.

Ainda sobre o estudo publicado pelo juiz federal, levando-se em conta o que dispõe o direito comparado sobre a prova indiciária e o delito de lavagem de dinheiro, com brilhantismo Moro (2010) esclareceu:

tem-se entendido que a prova indiciária é fundamental no processo por crime de lavagem de dinheiro, inclusive quanto à prova de que o objeto da lavagem é produto de um crime antecedente. Assim, por exemplo, nos Estados Unidos, tal prova pode ser satisfeita com elementos circunstanciais, a expressão usualmente utilizada para representar a prova indireta.

Por outro lado, sob a ótica defensiva, muitas críticas têm enaltecido a discussão sobre a possibilidade da utilização da prova indiciária do crime antecedente como fundamento à condenação pelo delito de branqueamento de capitais.

Os principais argumentos defensivos, principalmente os que têm aportado em sede acadêmica, residem, basicamente, na alegação de violação dos princípios constitucionais da legalidade e da ampla defesa, bem como da violação da vedação da analogia in mallam parte.

Primeiramente, no que se refere ao princípio da legalidade, as principais críticas que têm surgido, repito, em sede acadêmica, é sobre eventual mácula ao princípio da legalidade, uma vez que a Lei 9.613/96, que trata do delito de lavagem de dinheiro no Brasil, ao dispor sobre a prova 
do crime antecedente apenas exigiu indícios suficientes de provas do crime antecedente para a propositura da ação penal pelo membro do Ministério Público. Vejamos:

Art. $2^{\circ} \mathrm{O}$ processo e julgamento dos crimes previstos nesta Lei:

$\S 1^{\circ} \mathrm{A}$ denúncia será instruída com indícios suficientes da existência do crime antecedente, sendo puníveis os fatos previstos nesta Lei, ainda que desconhecido ou isento de pena o autor daquele crime.

Assim, a decisão judicial de condenação por crime de lavagem de dinheiro, fundamentada, unicamente, em indícios do crime antecedente, não teria suporte na Lei 9.613/96.

Em que pese o conteúdo dos argumentos ora explanados, os mesmos não merecem guarida, uma vez que não há ofensa à legalidade. As normas infralegais não podem ser interpretadas apenas de forma literal. No caso ora em estudo é crucial lançar mão da interpretação sistemática, ou seja, a legislação extravagante se complementa com o sistema penal, processual penal, etc. Neste sentido, quando se trabalha com estudo do valor probatório, é certo que não existe no nosso ordenamento jurídico um grau de maior ou menor valor de provas. Não se podem graduar as provas, simplesmente.

Vigora no Direito Processual Brasileiro o livre convencimento fundamentado do juiz; ou seja, o magistrado, diante das provas produzidas em determinado processo, exerce seu livre convencimento motivado, selecionando as provas que melhor se ajustam ao caso concreto, sempre esclarecendo os fundamentos de sua decisão. Tal princípio vem disposto no artigo 155 do Código de Processo Penal.

O ministro Francisco Campos, na Exposição de Motivos do Código de Processo Penal, já elucidava:

não é pré-fixada uma hierarquia de provas: na livre apreciação destas o Juiz formará honesta e lealmente sua convicção. Todas as provas são relativas: nenhuma delas terá, ex vi legis, valor decisivo, ou necessariamente 
maior prestígio que outra. Se é certo que o juiz fica adstrito às provas constantes dos autos, não é menos certo que não fica subordinado a nenhum critério apriorístico no apurar, através delas, a verdade material (BONFIM, 2009, p. 54).

Acerca da prova indiciária, também é certo que o juiz pode decidir somente por ela, não há dispositivo legal que determine que o julgador deve se ater somente à prova direta.

Pode o juiz julgar a partir das provas indiretas e diretas, ou ainda exclusivamente por apenas uma delas, desde que o conjunto probatório leve ao seu convencimento motivado. Isto é, eventual prova indireta de que irá dispor o magistrado deve conter um conjunto probatório suficiente para a decisão - ou seja, não basta a prova indiciária do delito antecedente de forma isolada, como já nos referimos, é necessário que se forme um conjunto de várias provas indiciárias, as quais resultarão em um arcabouço robusto, convincente o suficiente para retirar qualquer tipo de incerteza do julgador.

Por tudo isto, é impróprio a alegação de que o julgamento a partir de provas indiciárias do crime antecedente na lavagem de dinheiro afronte o princípio constitucional da legalidade.

Sustenta-se, ainda, a possibilidade de afronta ao princípio constitucional da ampla defesa, uma vez que a prova indiciária não revela claramente quais os pontos a serem debatidos pelo acusado. Não merece refúgio tal sustentação. É patente que a ampla defesa é princípio constitucional incólume e deve ser respeitado em todas as fases processuais, sendo velado pelo Ministério Público e pelo próprio magistrado, em sua amplitude.

Entretanto, sustentar que seria afrontar a ampla defesa a impossibilidade de exercê-la em sua plenitude porque a prova indiciária não determina com clareza qual ou quais os motivos determinantes da condenação é por demais equivocado ou até falta de leitura do operador do direito que sustenta tal desiderato.

Como estudado alhures, a prova indiciária tem expressa disposição legal no Código de Processo Penal Brasileiro. E mais: sua utilização 
deve estar fundamentada em fatos e circunstâncias que levam ao fato a ser provado. Este encadeamento lógico deve ser a essência do debate no caso concreto - ou seja, a defesa deve ser exercida levando-se em conta os fatos e as circunstâncias que deram origem à prova indiciária.

A prova indiciária não é presunção. Esta sim dificulta ou impossibilita a defesa, porque fundamentada no intelectivo da pessoa. $\mathrm{O}$ indício não. Ressalte-se, porque materializado em fatos e circunstâncias.

Por fim, argumentou-se também eventual afronta ao princípio da proibição da analogia in mallam parte, uma vez que se estaria utilizando de caso semelhante para condenação do acusado. Inadequada a alegação. Veja-se, a lacuna no direito existe quando o juiz não consegue preencher o "espaço vazio" ante a falta de normas que compõe o instituto jurídico no caso concreto. Diante disto, lança mão o intérprete da analogia, dos costumes, da equidade ou dos princípios gerais do direito, evitando que o operador do direito se torne um legislador.

O brocardo jurídico nullum crimen nulla poena sine lege stricta trata da proibição da utilização da analogia para fundamentar uma condenação criminal ou ainda para agravar uma pena. Não é o caso da discussão que se propõe. Nos processos concretos em que se utilizou da prova indiciária do crime antecedente para sustentar a condenação por delito de lavagem de dinheiro, não houve, em hipótese alguma, utilização de caso semelhante para se preencher lacuna do direito; pelo contrário, houve condenação criminal motivada em provas admitidas em direito, isto é, por meio de um conjunto probatório robusto de provas indiciárias.

Sobre o tema, a propósito podem ser citadas as seguintes decisões (MORO, 2010):

ACR 2000.71.00.041264-1 (2007) e ACR 2000.71.00.037905-4 (2006) Tribunal Regional Federal da $4^{\text {a }}$ Região, onde decidiu o Tribunal que não é exigida prova cabal dos delitos antecedentes, bastando apenas indícios da prática das figuras mencionadas nos incisos I a VII para que se complete a tipicidade. 
Assim, diante do que foi exposto, não restam dúvidas de que é perfeitamente legal a utilização das provas indiciárias do crime antecedente para subsidiar condenação criminal por delitos de lavagem de dinheiro, uma vez que se trata de delitos autônomos (antecedente e lavagem), com previsão legal específica e ainda porque em perfeita sintonia com o Sistema Processual Penal Brasileiro.

Ademais, ao se pretender admitir o contrário, ou seja, a impossibilidade da utilização da prova indiciária do delito antecedente, a fundamentação de condenações por crime de branqueamento de capitais estar-seia caminhando para trás, de encontro à evolução do Direito e do próprio Estado Democrático.

\section{Referências}

ALVARENGA, C. de A. Ações internacionais de combate à lavagem de dinheiro em instituições financeiras: uma visão geral do grupo de ação financeira sobre lavagem de capitais. ago. 2003. Disponível em: <http://jus2.uol.com.br/doutrina/ texto.asp?id=4571\&p=1 . Acesso em: 4 maio 2010.

AZEVEDO, V. de. Curso de direito judiciário penal. São Paulo: Saraiva, 1958. v. II.

BALDI, L. A prova indiciária e a lavagem de dinheiro: sua natureza, limites e aplicação no controle da reciclagem de capitais ilícitos. 2009. 128 f. Monografia (Trabalho de Conclusão de Curso de Direito). 2009.

BONFIM, E. M. Curso de Processo Penal. 4. ed. São Paulo: Saraiva, 2009.

BRASIL. Presidência da República. Lei n. 9.613, de 3 de março de 1998. Dispõe sobre os crimes de "lavagem" ou ocultação de bens, direitos e valores; a prevenção da utilização do sistema financeiro para os ilícitos previstos nesta Lei; cria o Conselho de Controle de Atividades Financeiras (COAF), e dá outras providências. Diário Oficial [da] República Federativa do Brasil, Brasília, Congresso Nacional, 3 mar. 1998. Disponível em: <http://www.planalto.gov.br/ccivil/leis/ L9613.htm>. Acesso em: 31 ago. 2010. 
CAPEZ, F. Curso de Processo Penal. São Paulo: Saraiva, 2005.

CONSELHO DE CONTROLE DE ATIVIDADES FINANCEIRAS - COAF. Disponível em: <https://www.coaf.fazenda.gov.br/conteudo/sobre-lavagem-de-dinheiro-1/ fases $>$. Acesso em: 25 fev. 2009.

DELLEPIANE, A. A nova teoria da prova. Campinas: Minelli, 2004.

LILLEY, P. Lavagem de dinheiro: negócios ilícitos transformados em atividades legais. São Paulo: Futura, 2001.

MORO, S. F. Autonomia do crime de lavagem de dinheiro e prova indiciária. Disponível em: <http://www2.cjf.jus.br/ojs2/index.php/cej/article/viewFile/1018/1184>. Acesso em: 4 maio 2010.

MOURA, M. T. R. de A. A prova por indícios no processo penal. Rio de Janeiro: Lumen Juris, 2009.

SILVEIRA, S. S. da. A prova indiciária no processo penal. Disponível em: <http://www.buscalegis.ufsc.br/revistas/index.php/buscalegis/article/viewFile/17080/16644>. Acesso em: 4 maio 2010.

Recebido: 20/05/2010

Received: 05/20/2010

Aprovado: 10/08/2010

Approved: 08/10/2010 